\begin{tabular}{|c|l|}
\hline Title & A eromagnetic survey using an unmanned autonomous helicopter over Tarumae V olcano, northern Japan \\
\hline Author(s) & $\begin{array}{l}\text { Hashimoto, Takeshi; Koyama, Takao; Kaneko, Takay uki; Ohminato, Takao; Y anagisawa, Takatoshi; Y oshimoto, } \\
\text { Mitsuhiro; Suzuki, Eiichi }\end{array}$ \\
\hline Citation & $\begin{array}{l}\text { Exploration Geophysics, 45(1), 37-42 } \\
\text { https://doi.org/40.1071/EG12087 }\end{array}$ \\
\hline Issue Date & 201403 \\
\hline Doc URL & http://hdl.handle.net/2115/56579 \\
\hline Type & article(author version) \\
\hline File Information & EG_45_37-.pdf \\
\hline
\end{tabular}

Instructions for use 


\section{AEROMAGNETIC SURVEY USING AN UNMANNED AUTONOMOUS HELICOPTER OVER TARUMAE VOLCANO, NORTHERN JAPAN}

Takeshi Hashimoto

Institute of Seismology and Volcanology, Faculty of Science, Hokkaido University, N10W8, Kita-ku, Sapporo, Hokkaido 060-0810, Japan.

Phone: +81-11-706-4677

Facsimile: +81-746-7404

E-mail: hasimoto@mail.sci.hokudai.ac.jp

Takao Koyama

Earthquake Research Institute, University of Tokyo, Yayoi 1-1-1, Bunkyo-ku, Tokyo 1130032, Japan

E-mail: tkoyama@eri.u-tokyo.ac.jp

Takayuki Kaneko

Earthquake Research Institute, University of Tokyo, Yayoi 1-1-1, Bunkyo-ku, Tokyo 1130032, Japan

E-mail: kaneko@eri.u-tokyo.ac.jp

Takao Ohminato

Earthquake Research Institute, University of Tokyo, Yayoi 1-1-1, Bunkyo-ku, Tokyo 1130032, Japan

E-mail: takao@eri.u-tokyo.ac.jp

Takatoshi Yanagisawa

Japan Agency for Marine-Earth Science and Technology, 2-15, Natsushima-cho, Yokosuka, Kanagawa 237-0061, Japan

E-mail: yanagi@jamstec.go.jp 
Mitsuhiro Yoshimoto

Earth and Planetary System Science, Faculty of Science, Hokkaido University, N10W8, Kitaku, Sapporo, Hokkaido 060-0810, Japan.

Email: m-yoshi@mail.sci.hokudai.ac.jp

Eiichi Suzuki

River Centre of Hokkaido, 5-1, N7W4, Kita-ku, Sapporo, Hokkaido 060-0807, Japan

Email: e.suzuki@ric.or.jp

Date: July 18, 2014

Left Running Heading: $\quad$ Hashimoto, Koyama, Kaneko, Ohminato, Yanagisawa, Yoshimoto and Suzuki

Right Running Heading: Aeromagnetic Survey Using an Autonomous Helicopter 


\section{ABSTRACT}

Unmanned aerial vehicles (UAVs) have recently drawn attention in various research fields for their ability to perform measurements, surveillance, and operations in hazardous areas. Our application is volcano surveillance, in which we used an unmanned autonomous helicopter to conduct a dense low-altitude aeromagnetic survey over Tarumae volcano, northern Japan.

In autonomous flight, we demonstrated positioning control with an accuracy of approximately $10 \mathrm{~m}$, which would be difficult for an ordinary crewed vehicle. In contrast to ground-based magnetic measurement, which is highly susceptible to local anomalies, the field gradient in the air with a terrain clearance of 100 to $300 \mathrm{~m}$ was fairly small at $1 \mathrm{nT} / \mathrm{m}$. This result suggests that detection of temporal changes of an order of $10 \mathrm{nT}$ may be feasible through a direct comparison of magnetic data between separate surveys by means of such a system, rather than that obtained by upward continuation to a common reduction surface. We assessed the temporal magnetic changes in the air, assuming the same remagnetising source within the volcano that was recently determined through ground surveys. We conclude that these expected temporal changes would reach a detection level in several years through a future survey in the air with the same autonomous vehicle.

Key words: aeromagnetic survey, unmanned autonomous helicopter, Tarumae volcano, geomagnetism. 


\section{INTRODUCTION}

In recent years, unmanned autonomous helicopters have been applied to observations of volcanic activity. For example, a group headed by the Earthquake Research Institute, University of Tokyo conducted several experiments at Izu-Oshima, Sakurajima, and Kirishima volcanoes (Kaneko et al., 2011). Although such unmanned helicopters are commercially used to spray pesticides on farmland, they can also provide a means for quick surveillance of areas devastated by natural disasters such as flooding. However, actual performance over volcanoes in mountainous areas remains uncommon due to the high degree of difficulty involved in such an application. In this regard, a higher number of field experiments that can be conducted over volcanoes would lead to greater availability of unmanned helicopters both for scientific research purposes and for emergency responses during eruptive crises. In 2011, we began to conduct such experiments over Tarumae volcano in northern Japan in cooperation with the Hokkaido Regional Development Bureau, which owns a fleet of unmanned helicopters. In the first experiment we performed an airborne magnetic survey and aerial video imaging of the summit area in addition to an experiment of remote installation / retrieval of a seismometer.

A manned helicopter can perform these tasks as well if the volcano is calm. However, under elevated volcanic activity, a crewed flight over an active crater with a low altitude is generally unsafe and ground-level approaches to the volcano are restricted. Thus in many cases, realtime monitoring at stations close to active areas may be lost, once the instruments on the ground are damaged by an eruption. An unmanned helicopter has the potential to resolve such issues because it is capable of performing safe surveillance and temporary alternative measurements from remote sites. This study aims to establish techniques for safe and 
efficient application of this new measurement platform to volcanic fields. In particular, we present the first results of airborne magnetic mapping and discuss the feasibility of detecting temporal changes in magnetic fields associated with volcanic activities.

\section{BACKGROUND}

\section{Magnetic Measurements on Volcanoes}

In general, a volcano is associated with magnetic anomalies because magnetic materials are abundant in most volcanic rocks. Such anomalies in the magnetic field reflect the heterogeneity of near-surface magnetisation that originates from chemical composition, mode of emplacement of volcanic deposits, and the posterior demagnetisation due to heating or alteration. Analyses of magnetic anomalies on the ground or in the air enable determination of such heterogeneities at the shallow subsurface. Magnetisation in a rock is prone to decrease when heated, with most of the loss occurring at approximately $600{ }^{\circ} \mathrm{C}$. This property facilitates detection of subsurface heating/cooling from the changes in the magnetic field.

Numerous studies have reported such thermo-magnetic effects. For example, Hurst and Christoffel (1973), on the basis of repeated magnetic ground measurements, detected remarkable demagnetisation in the crater area of White Island, New Zealand. Tanaka (1993) monitored the magnetic field near the active crater of Aso volcano, Japan to determine that gradual demagnetisation (due to heating) occurred beneath the crater when the surface activity appeared calm; however, rapid remagnetisation (on cooling) followed explosive events. 
Kanda et al. (2010), on the basis of continuous monitoring, detected a gradual build-up of thermal demagnetisation that coincided with localised ground inflation at Kuchi-erabu-jima volcano, Japan. Further, Nakatsuka et al. (2009) and Hashimoto et al. (2011) both reported temporal changes in the magnetic field between separate airborne surveys by using a crewed helicopter at Asama and Usu volcanoes, respectively.

Such information on temperature changes in a volcanic edifice, together with other observations such as the ground deformation and seismic activity, provide better understanding of on-going volcanic activities. Magnetic measurements obtained during an eruptive period may also be useful in forecasting subsequent activity of a volcano.

\section{Tarumae Volcano}

Mt. Tarumae is a post-caldera volcano of Shikotsu caldera which is presently known as Lake Shikotsu. Tarumae began its volcanic activity approximately 9,000 years ago. The edifice is mainly composed of pyroclastic deposits due to explosive eruptions (Furukawa and Nakagawa, 2010). The summit crater with a diameter of approximately $1 \mathrm{~km}$ forms a flat atrio fringed with topographic highs that include Nishi-yama (western peak) and Higashiyama (eastern peak). A lava dome produced through the 1909 eruption is located at the centre of the atrio; Tarumae has not experienced magmatic eruptions since that time. Although recent observations show no remarkable ground deformation to suggest an accumulation of magma, fumaroles and geothermal anomalies are currently seen in addition to micro-seismicity beneath the summit dome. The occurrence of activities fluctuates among periods. Most recently, sulphur-rich altered volcanic materials with high- 
temperature gas effused from the southern slope of the lava dome in May 2011; however, no remarkable change in micro-seismicity was recognised.

In this section, we summarise the preceding studies on geomagnetism of Tarumae volcano. Sakuma and Murase (1956) made an approximated estimation of magnetisation of the volcano by mapping the geomagnetic inclination anomaly. An aeromagnetic survey conducted by Geographical Survey Institute of Japan in 2000 provided a total intensity map at a relatively high altitude of 2,000 m ASL, which revealed a positive magnetic anomaly chain connecting Tarumae, Fuppushi, Shikotsu, and Eniwa volcanoes (locations shown in Figure 1). The Japan Meteorological Agency (JMA) has repeatedly conducted irregular magnetic surveys on the ground since 1998, which has revealed clear magnetic changes that suggest a thermal demagnetisation approximately in year 2000 (Seismology and Volcanology Research Department, MRI, 2008). Hokkaido University and JMA has conducted denser and more frequent measurements since 2010. This effort successfully resulted in the detection of cooling magnetisation, which is plausibly associated with a May 2011 effusive event of sulphurous materials (Hokkaido University and Sapporo District Meteorological Observatory, unpublished data). The magnetic field continued to change thereafter at roughly a constant rate until the present (October 2012). An equivalent magnetic dipole is located beneath the summit dome at a depth of $500 \mathrm{~m}$ and an estimated remagnetisation rate of $1 \times 10^{7} \mathrm{Am}^{2} / \mathrm{y}$. For these reasons, Tarumae was deemed a suitable experiment field for performing repeated aeromagnetic measurements by using an unmanned helicopter to determine temporal variations. 


\section{MEASUREMENTS}

In collaboration with the Hokkaido Regional Development Bureau, we performed an aeromagnetic survey over Mt. Tarumae on September 27, 2011, in which the total magnetic field was intensively mapped over the summit area, including the lava dome. This study was the first in which low-altitude aeromagnetic measurements were obtained for this volcano. An unmanned autonomous helicopter (YAMAHA, Rmax-G1) was used as the measurement platform (Figure 2). The length, maximum payload, and maximum flight duration of the helicopter were $3.6 \mathrm{~m}, 10 \mathrm{~kg}$ and $80 \mathrm{~min}$, respectively. Although it was designed to fly autonomously with the aid of real-time GPS navigation, human operators guide the helicopter via radio control at take-off and landing. In-vehicle base stations were set up at the northern and southern flanks of the volcano at a distance of approximately 1.5 $\mathrm{km}$ from the target area (Figure 1). To ensure that the required flight altitude could be maintained, we reduced fuel at the expense of flight endurance. Once the helicopter was guided into the target area, it flew autonomously along programmed courses. Real-time positioning was achieved by using two GPS receivers (NovAtel Inc., OEM4-RT20) mounted on the helicopter body and the vehicle at the base. Wireless communication between the base station and the helicopter with 0.8 and $2.3 \mathrm{GHz}$ bands assumed the roles of real-time navigation and monitoring of the conditions in the air such as position, tilt, wind velocity, and visibility. The total magnetic field was measured with an optical-pumping magnetometer (Geometrics, G858). The sensor was towed on a $4.5 \mathrm{~m}$ cable to avoid magnetic disturbances from the helicopter body (Figure 3). Moreover, we conducted continuous ground-based magnetic measurement at the southeast foot of the volcano as a reference for the reduction of geomagnetic disturbances of ionospheric origin (magnetic reference, left panel in Figure 1). The reference magnetometer was synchronised in time with a GPS clock in posterior data processing. All of the magnetic and GPS data were sampled at $10 \mathrm{~Hz}$. In this study we 
considered that the offset and swing between the GPS receiver on the helicopter and the towed magnetic sensor was within positioning errors and no correction was performed. Although nominal relative positioning accuracy was $20 \mathrm{~cm}$, absolute accuracy was presumed to be a few meters, as the positions of base stations were not determined to higher accuracy. We note that geomagnetic weather was disturbed during the survey flight; however, we do not consider that this disturbance affected our analysis, because of the proximity of the reference station to the survey.

The actual flight paths are shown in Figure 4, in which the magnetic total field is presented with a colour scale. A dipolar magnetic anomaly of $\pm 500 \mathrm{nT}$ due to the topography is clearly recognised. Terrain clearance over the summit area was approximately 100 to $300 \mathrm{~m}$, and the maximum altitude was approximately 1,300 m ASL, as shown in the vertical projection of the flight paths in Figure 5. The average velocity of the flight was $5 \mathrm{~m} / \mathrm{s}$. Flight altitude during the autonomous operation remained nearly constant for each course. We compared the actual flight traces with the programmed paths to verify the accuracy of the positioning control. The deviation from the programmed paths is displayed as a histogram in Figure 6. Approximately $60 \%$ of the programmed paths were traced within a deviation of $5 \mathrm{~m}$ and roughly $85 \%$ for a deviation of $10 \mathrm{~m}$. The remaining $15 \%$ with larger deviations were attributed to a strong wind that occurred at the northern and southern margins of the summit atrio. In terms of altitude, approximately $90 \%$ of the survey lines were flown within an accuracy of $2 \mathrm{~m}$. Thus, flight control was mostly satisfactory except for these anomalies, considering that such an accurate control is generally difficult also for crewed flights. Moreover, in contrast to typical measurements on the ground, the magnetic gradient along the actual traces in the air was fairly small at generally less than $\pm 1 \mathrm{nT} / \mathrm{m}$, as shown in Figure 7 . 
Hence, when the positioning repeatability is considered, we conclude that the error range in our magnetic field measurement was roughly $\pm 10 \mathrm{nT}$. This result suggests that detection of temporal magnetic changes through a direct comparison between separate airborne surveys is more feasible by means of an unmanned helicopter rather than by a conventional crewed vehicle, in which traces of the separate surveys cannot be regarded identical; thus a certain procedure of common surface reduction is generally required. Although it is not easy to show a typical error in detection of temporal magnetic changes through crewed helicopter surveys, \pm 10 nT may be referred to as a recent example from Usu volcano (Hashimoto et al., 2011), in which temporal changes in 10 years between separate airborne surveys were discussed through an upward continuation to a common reduction surface with the aid of the generalized mis-tie control method (Nakatsuka et al., 2009). In other words, a comparable detection level is achieved through unmanned helicopter surveys even without any interpolation or extrapolation procedures.

\section{MAGNETIC FIELD ANOMALY}

As a very preliminary analysis for the magnetic anomaly obtained from the first survey, we estimated an averaged magnetisation of the target area. For the purpose of eliminating the geomagnetic field variations of upper atmospheric origins, we calculated a simple difference between the magnetic data in the air and that at the ground reference with synchronised time. We then resampled the magnetic data into a 20 s-base to make the along-line data spacing approximately equal to the across-line. We used the digital terrain model of a $10 \mathrm{~m}$ mesh published by Geospatial Information Authority of Japan to calculate the terrain-related 
anomaly. We modelled the terrain as an assembly of vertical prisms. Each prism was assumed to be magnetised uniformly in a direction parallel to the present geomagnetic field (declination $9.1^{\circ} \mathrm{W}$, inclination $57.1^{\circ}$ ). The bottoms of the prisms were common, below which a null magnetisation was assumed. We modelled a uniformly magnetised terrain that minimised the following objective function $\Phi_{0}$ :

$$
\Phi_{0}=\sum_{i=1}^{N}\left\|d_{i}-\sum_{j=1}^{M} A_{i j} J_{0}\right\|^{2}
$$

where $d_{\mathrm{i}}$ is the measured magnetic field at the ith position. The summation limit $N \quad(=227)$ is the total number of magnetic data for the inversion. The second term in the right hand side of equation (1), $A_{\mathrm{ij}} J_{0}$, represents the magnetic field at the ith position, which is produced by the $j$ th prism with a magnetisation of $J_{0} . \quad M$ is the total number of prisms considered. Topography was introduced for sufficiently wider area compared to the targe area in order to avoid edge effects. This forward calculation was based on the use of the methods by Bhattacharyya (1964) and its modified version by Kunaratnam (1981). We obtained $J_{0}$, which minimised the above objective function as follows:

$$
J_{0}=\frac{\sum_{i=1}^{N} \sum_{j=1}^{M} A_{i j} d_{i}}{\sum_{i=1}^{N}\left(\sum_{j=1}^{M} A_{i j}\right)^{2}}
$$

Then, the optimal magnetisation due to the uniform terrain $\left(J_{0}\right)$ was $5.3 \mathrm{~A} / \mathrm{m}$. This estimate appears reasonable as an averaged magnetisation of the summit atrio, considering the results from the geomagnetic dip anomaly by Sakuma and Murase (1956), which estimated the magnetisations of the summit lava dome and the other part of the edifice as $6-8 \mathrm{~A} / \mathrm{m}$ and 2-3 $\mathrm{A} / \mathrm{m}$, respectively. Contour maps of the airborne magnetic anomaly and the calculated 
magnetic anomaly due to the uniform terrain model are presented in Figures 8 and 9, respectively. The uniform model reconstructed the overall characteristics of the dipolar anomaly, although detailed anomalies in the summit atrio were not reproduced. Further 3D magnetisation modelling by introducing horizontal and vertical variations would be possible (e.g., Li and Oldenburg, 1996). However, we are not going to discuss here the detailed internal inhomogeneity of the volcanic edifice owing to the lack of other constraining data such as drilled cores.

\section{DETECTION OF EXPECTED MAGNETIC FIELD CHANGE}

In this section, we discuss the detection of the expected temporal change in the aeromagnetic field over Tarumae volcano in a future survey. As stated above, one of the authors (TH) and Sapporo District Meteorological Observatory, JMA, through repeated measurements on the ground since 2011, have detected temporal magnetic changes that suggest continuous cooling remagnetisation beneath the summit lava dome (Hokkaido University and Sapporo District Meteorological Observatory, unpublished data). An equivalent magnetic dipole of this event was located $500 \mathrm{~m}$ beneath the summit dome with an estimated remagnetisation rate of $1 \times 10^{7}$ $\mathrm{Am}^{2} / \mathrm{y}$. Assuming these parameters, we calculated the expected magnetic field change on the trajectories of the survey in 2011, and then generated a contour map as shown in Figure 10. This shows the southern half of a dipolar pattern ranging from -2 to $+5 \mathrm{nT}$ per year. On the basis of the typical error level of $\pm 10 \mathrm{nT}$ determined through the repeated surveys by the unmanned helicopter, the dipolar magnetic change is expected to reach a detection level in several years, provided that the volcano continues to remagnetise at the assumed rate. As 
the expected anomaly is large compared to the line spacing, an appropriate gridding prior to differentiating two surveys may aid detection of the change.

\section{CONCLUSIONS}

We conducted the first reported dense low-altitude aeromagnetic survey over Tarumae volcano using an unmanned helicopter in a field experiment for volcano surveillance. In autonomous flight we demonstrated positioning control within an accuracy of approximately $10 \mathrm{~m}$, which would be difficult for an ordinary crewed vehicle. The typical corresponding error range in the magnetic field measurement in the air was determined to be $\pm 10 \mathrm{nT}$ because the magnetic gradient along the actual trajectories was mostly within $\pm 1 \mathrm{nT} / \mathrm{m}$. This result suggests that temporal magnetic changes of an order of $10 \mathrm{nT}$ may be detectable through a direct comparison of magnetic data between separate surveys by means of this system, rather than from upward continuation to a common reduction surface. As a preliminary analysis, an average magnetisation of the target area was determined to be $5.3 \mathrm{~A} / \mathrm{m}$, which was consistent with the results of an earlier study.

We assessed temporal magnetic changes in the air on the basis of a currently remagnetising source beneath the lava dome and concluded that these temporal changes would reach the amplitude of a detection level in several years through future repeated surveys with the same autonomous flight system. 


\section{ACKNOWLEDGMENTS}

We sincerely thank Muroran Development and Construction Department, HRDB, for cooperation in the field experiments by offering the use of their unmanned helicopter system. We are grateful to Yamaha Motor Co., Ltd., for their technical support in the field operation. We used the 10 m mesh digital elevation map published by Geospatial Information Authority of Japan, for the inversion of magnetic anomalies. Special thanks are extended to Satoshi Okuyama of Hokkaido University for his effort in pre-processing the DEM data. This study was partially supported by the Ministry of Education, Culture, Sports, Science and Technology (MEXT) of Japan, under its Observation and Research Program for Prediction of Earthquakes and Volcanic Eruptions. Comments and suggestions of Dr. Mark Dransfield, two anonymous reviewers and Associate Editor contributed to improve the manuscript. 


\section{REFERENCES}

Bhattacharyya, B. K., 1964, Magnetic anomalies due to prism-shaped bodies with arbitrary polarization, Geophysics, 29, 517-531.

Furukawa, R. and Nakagawa, M., 2010, Geological Map of Tarumae Volcano, Geological Survey of Japan, 1-7.

Hashimoto, T., Utsugi, M., Nakatsuka, T., Okuma, S., Koyama, T. and Kanda, W., 2011, Temporal magnetic changes possibly due to cooling magmas as revealed by repeat helicopterborne surveys over an active volcano, Proceedings of the 10th SEGJ International Symposium, Kyoto, 276-279.

Hurst, A. W. and Christoffel, D. A., 1973, Surveillance of White Island volcano, 1968-1972, part 3 - Thermo-magnetic effects due to volcanic activity -: New Zeal. J. Geol. Geop., 16, 965-972.

Kanda, W., Utsugi, M., Tanaka, Y., Hashimoto, T., Fujii, I., Hasenaka, T. and Shigeno, N., 2010, A heating process of Kuchi-erabu-jima volcano, Japan, as inferred from geomagnetic field variations and electrical structure: J. Volcanol. Geoth. Res. 189, 158-171.

Kaneko, T., Koyama, T., Yasuda, A., Takeo, M., Yanagisawa, T., Kajiwara, K. and Honda, Y., 2011, Low-altitude remote sensing of volcanoes using an unmanned autonomous helicopter: an example of aeromagnetic observation at Izu-Oshima volcano, Japan, Int. J. Remote Sens., 32, 1491-1504.

Kunaratnam, K., 1981, Simplified expressions for the magnetic anomalies due to vertical rectangular prisms: Geophys. Prosp., 29, 883-890. 
Li, Y. and Oldenburg, D. W., 1996, 3-D inversion of magnetic data: Geophysics, 61, 394-408.

Nakatsuka, T., Utsugi, M., Okuma, S., Tanaka, Y. and Hashimoto, T., 2009, Detection of aeromagnetic anomaly change associated with volcanic activity: An application of the generalized mis-tie control method: Tectonophysics, 478, 3-18.

Sakuma, S. and Murase, T., 1956, Geophysical Studies of Volcanoes in Hokkaido, Japan: Geophys. Bull. Hokkaido Univ., 4, 1-24.

Seismology and Volcanology Research Department, Meteorological Research Institute, 2008, Studies on Evaluation Method of Volcanic Activity: Tech. Rep. Meteorol. Res. Inst., 53, 1306.

Tanaka, Y., 1993, Eruption mechanism as inferred from geomagnetic changes with special attention to the 1989-1990 activity of Aso Volcano, J. Volcanol. Geoth. Res., 56, 319-338. 


\section{FIGURE CAPTIONS}

\section{Fig. 1:}

(a) Location of Tarumae Volcano. (b) Intermediate-scale map of Shikotsu caldera. The magnetic reference station is shown with a solid circle at the bottom right. (c) Close-up map of the inset in panel (b). Solid squares indicate the base stations for helicopter control and monitoring. Horizontal and vertical axes are in the plane rectangular coordinates (PRC) of the 12 th system. The direction of PRCX is approximately 0.5 degrees westward from the geographical north in this area. Contour interval is $20 \mathrm{~m}$.

\section{Fig. 2:}

The unmanned helicopter (front) and the in-vehicle base station (back) used in this study.

Fig. 3:

Unmanned helicopter in operation of a magnetic survey. The magnetic sensor is suspended from a $4.5 \mathrm{~m}$ long wire.

\section{Fig. 4:}

Flight trajectories with magnetic field strength shown as a colour scale. 
Fig. 5:

Flight trajectories shown with topography projected by the cross-section AB in Figure 4.

Fig. 6:

Histogram of actual trajectory deviation from the programmed paths.

Fig. 7:

Histogram of magnetic gradient along the actual trajectory.

Fig. 8:

Aeromagnetic total field anomaly measured in this study. Contour interval is $100 \mathrm{nT}$. Crosses indicate data points. Coordinates are in plane rectangular coordinate (PRC). White contours indicate the topography.

Fig. 9:

Modelled magnetic field which is calculated from a uniform $(5.3 \mathrm{~A} / \mathrm{m})$ magnetised terrain. Contour interval is $100 \mathrm{nT}$. Crosses indicate data points. Coordinates are in plane rectangular coordinate (PRC). White contours indicate the topography.

Fig. 10: 
Synthetic total magnetic field change due to a remagnetising source beneath the summit lava dome at an altitude of $500 \mathrm{~m}$ ASL. Magnetic field changes were calculated on the same flight trajectory as an actual one in 2011, and then contoured. White lines indicate the flight paths. 


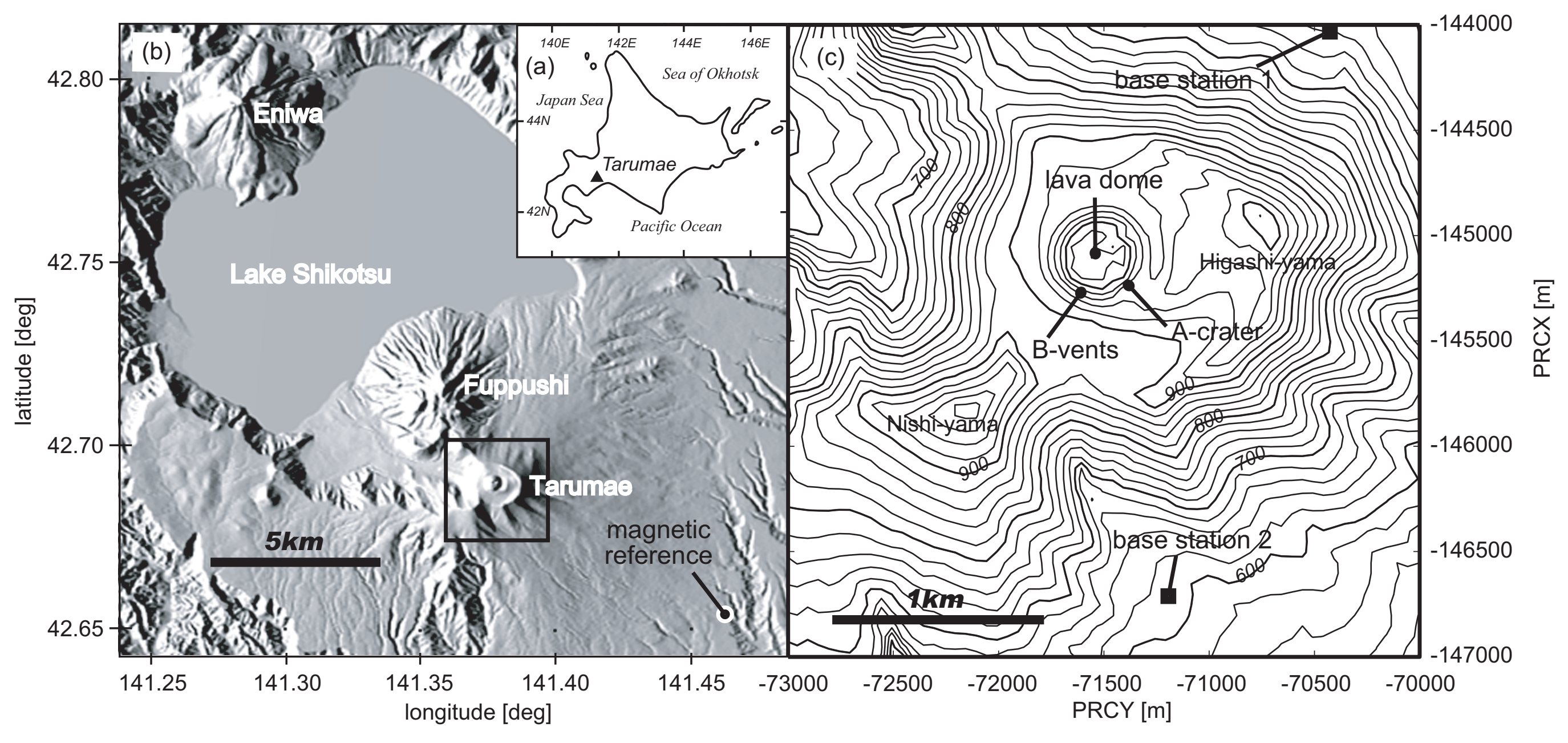

Figure 1 Hashimoto et al. 


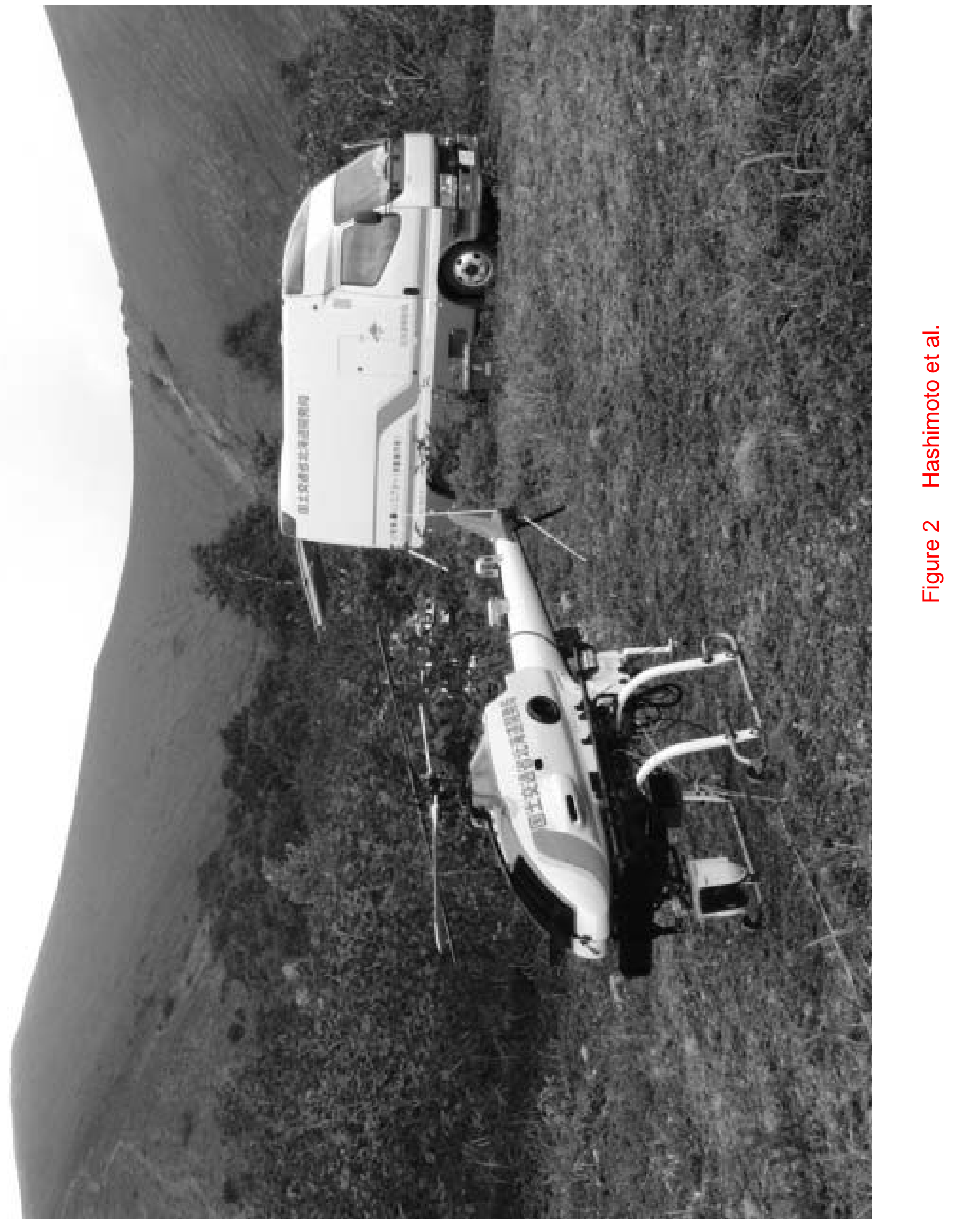




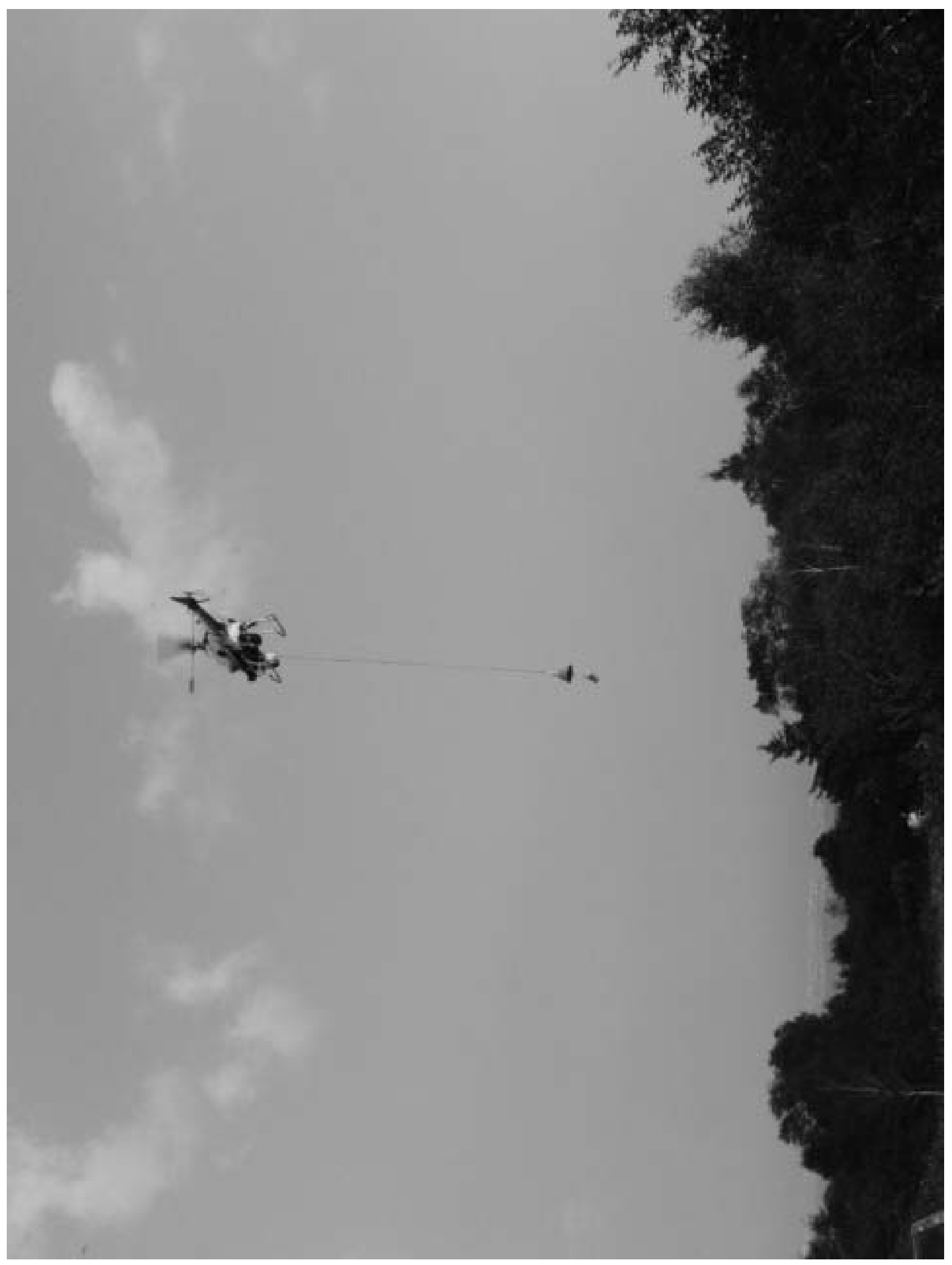

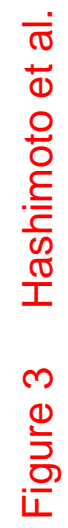




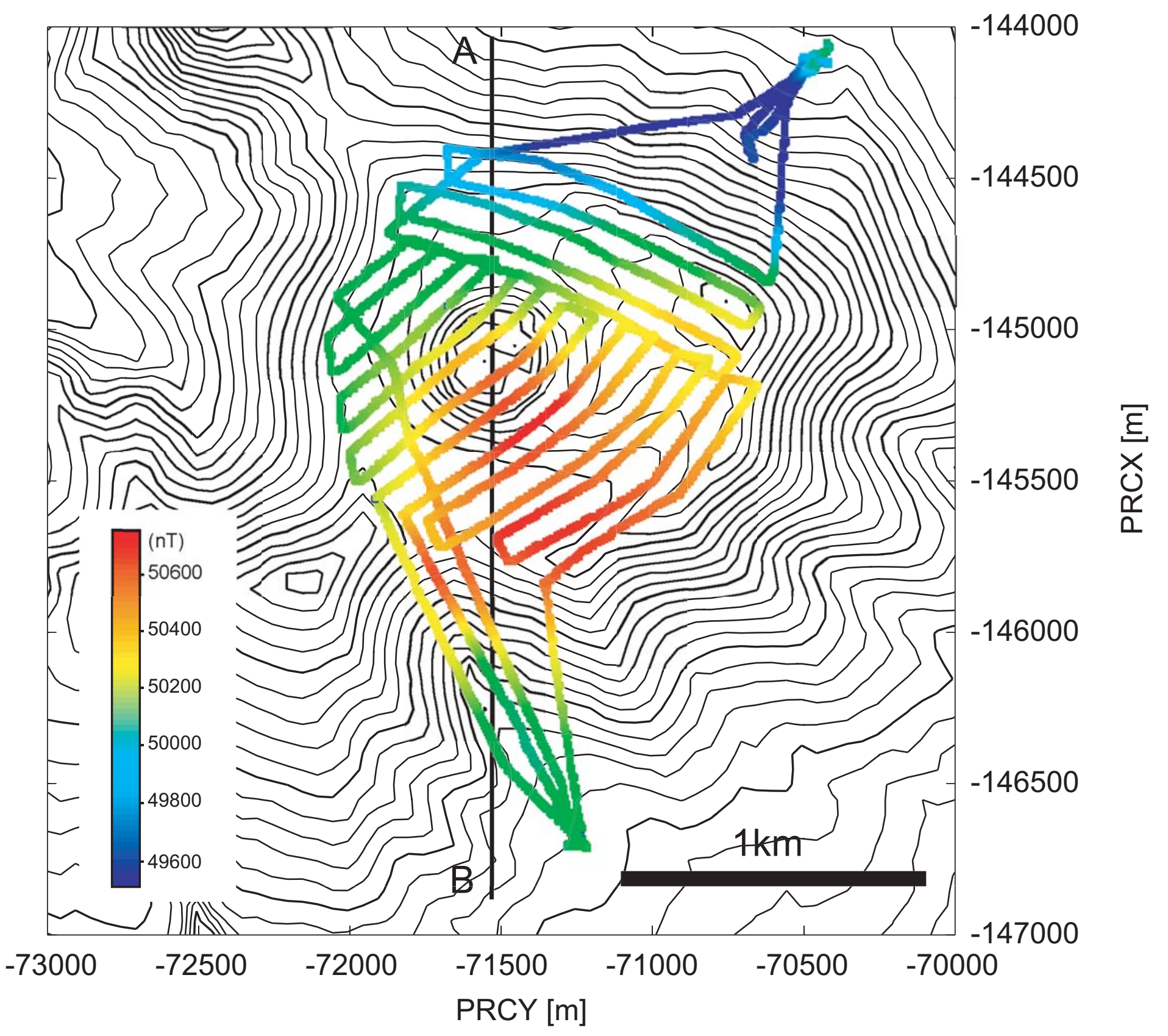

Figure 4 Hashimoto et al. 


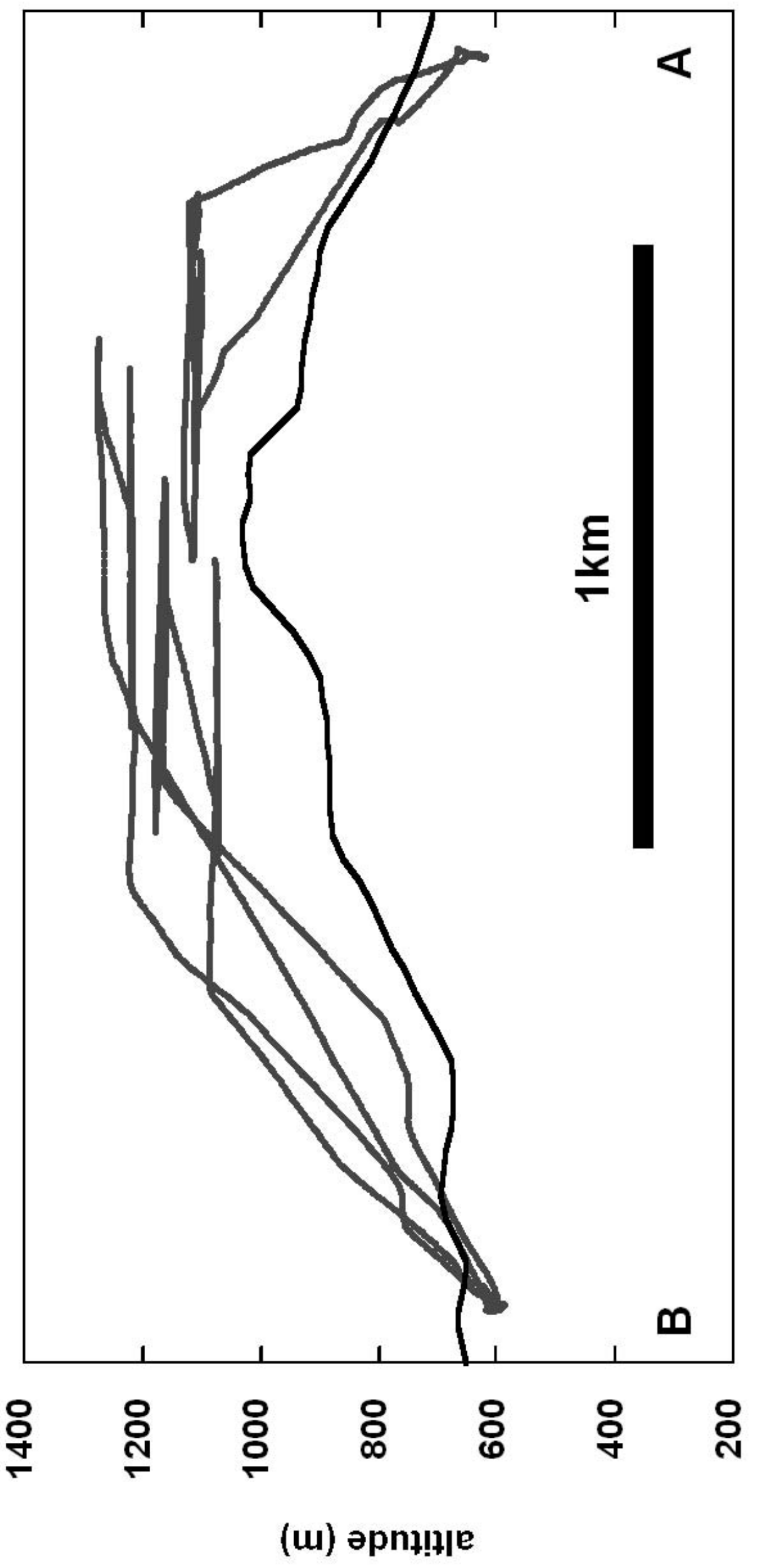

Figure 5 Hashimoto et al. 


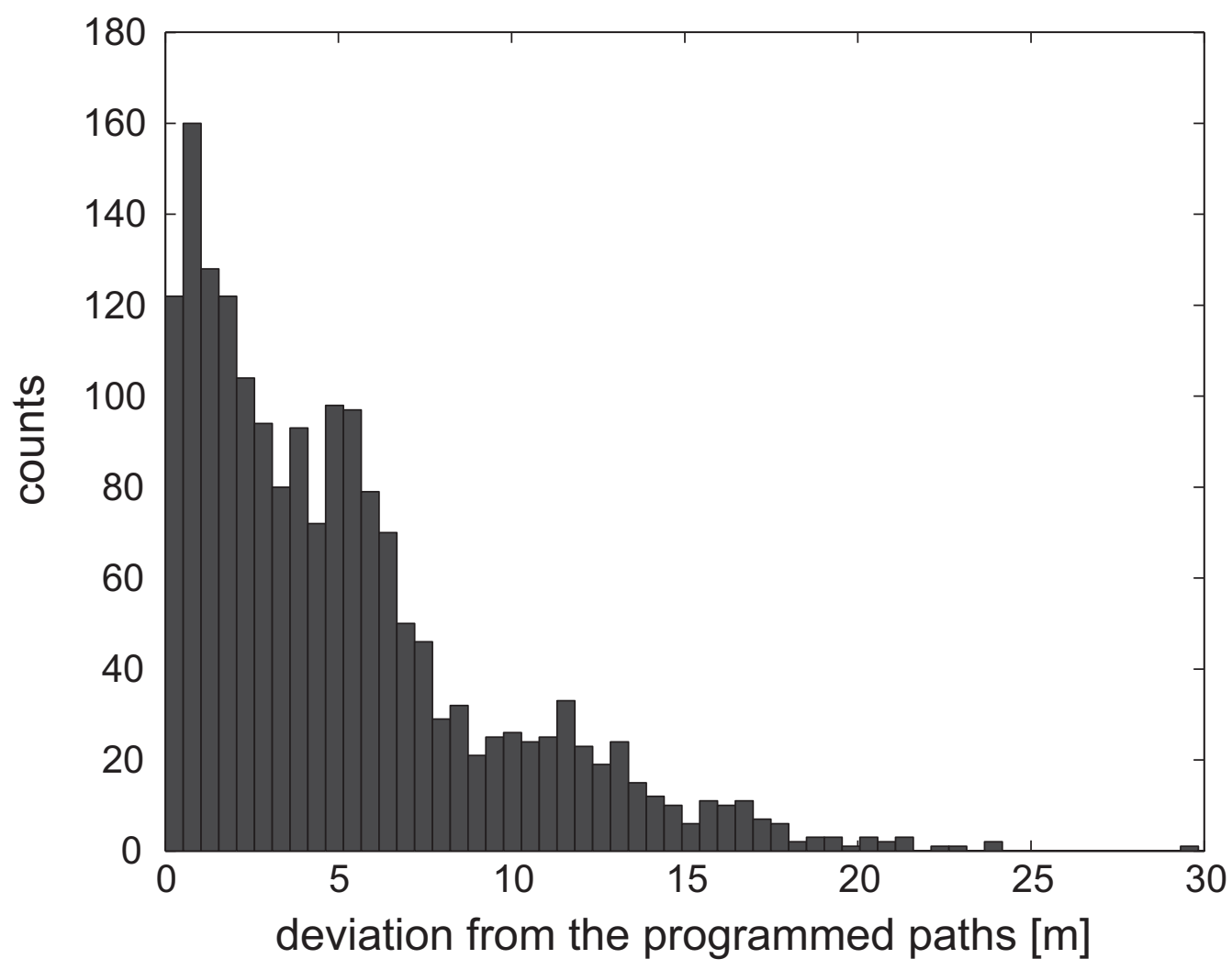

Figure 6 Hashimoto et al. 


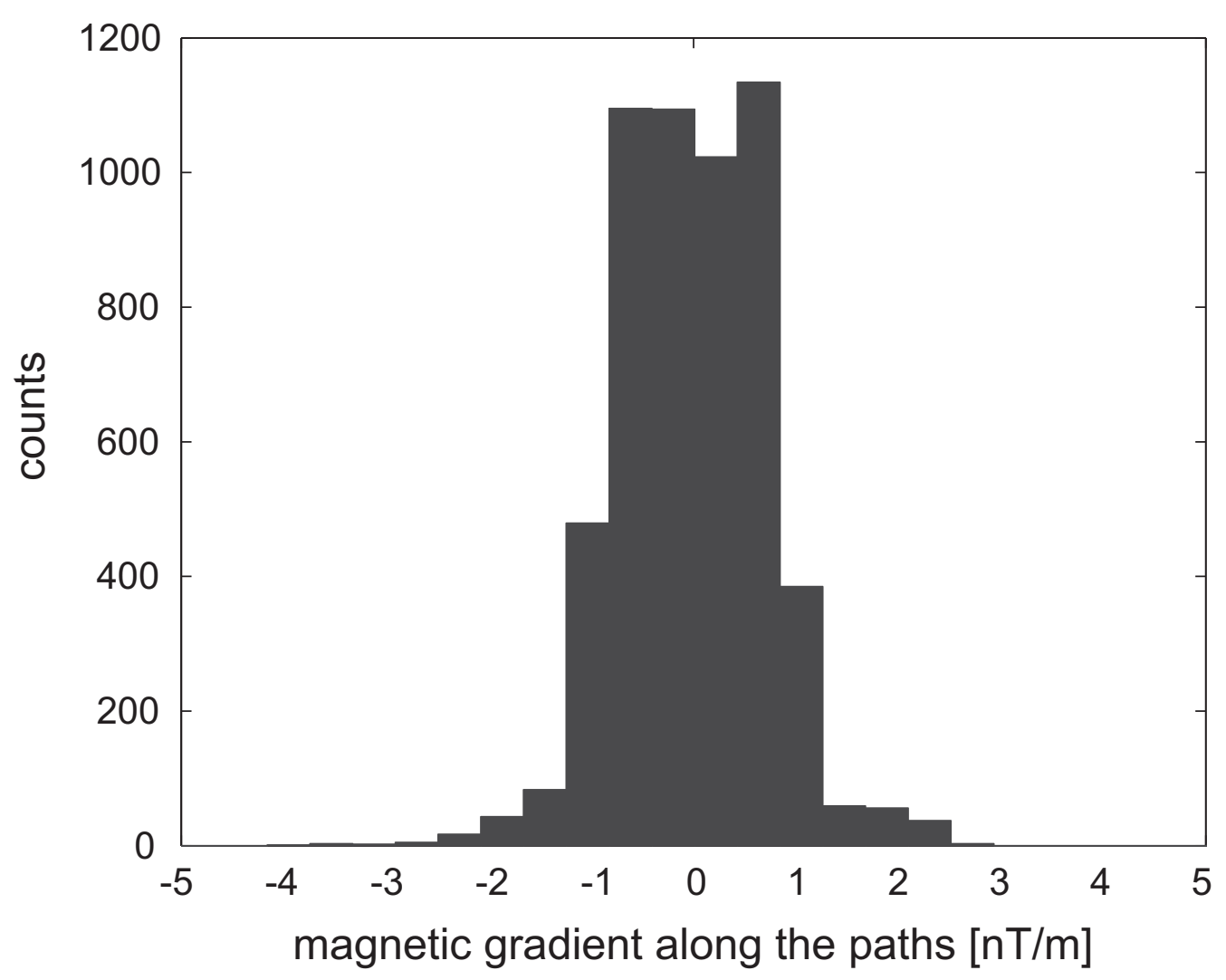

Figure 7 Hashimoto et al. 


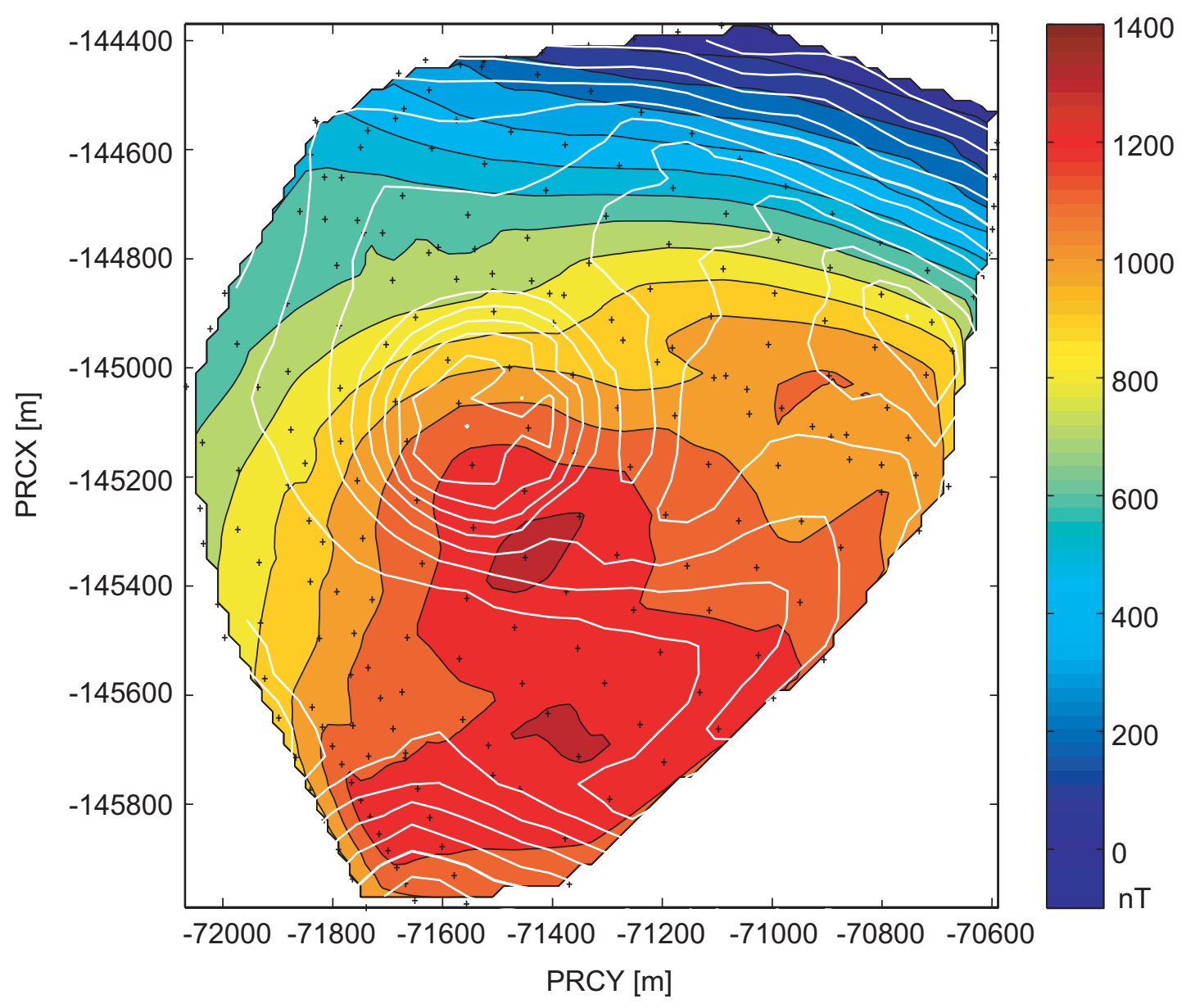

Figure 8 Hashimoto et al. 


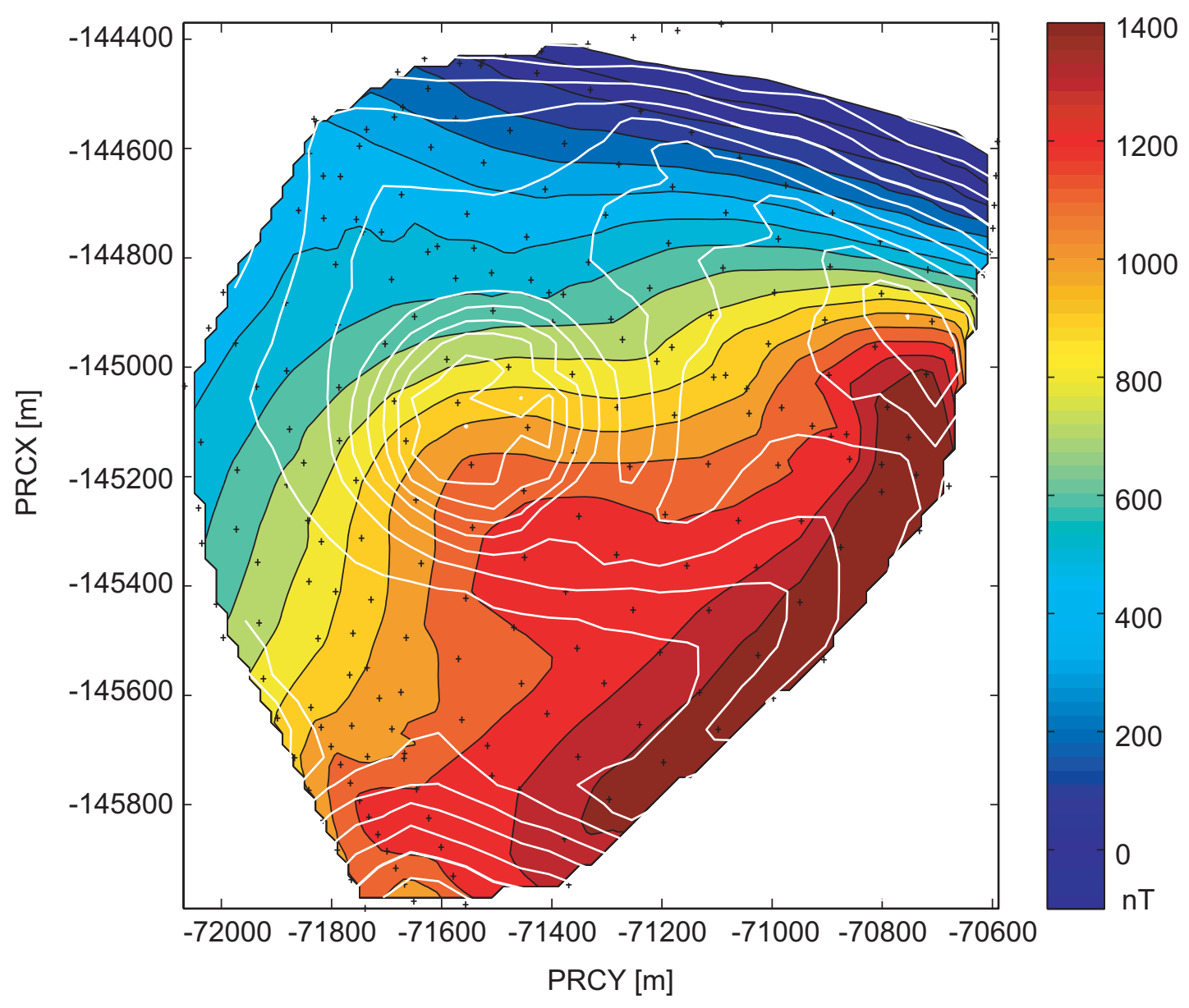

Figure 9 Hashimoto et al. 


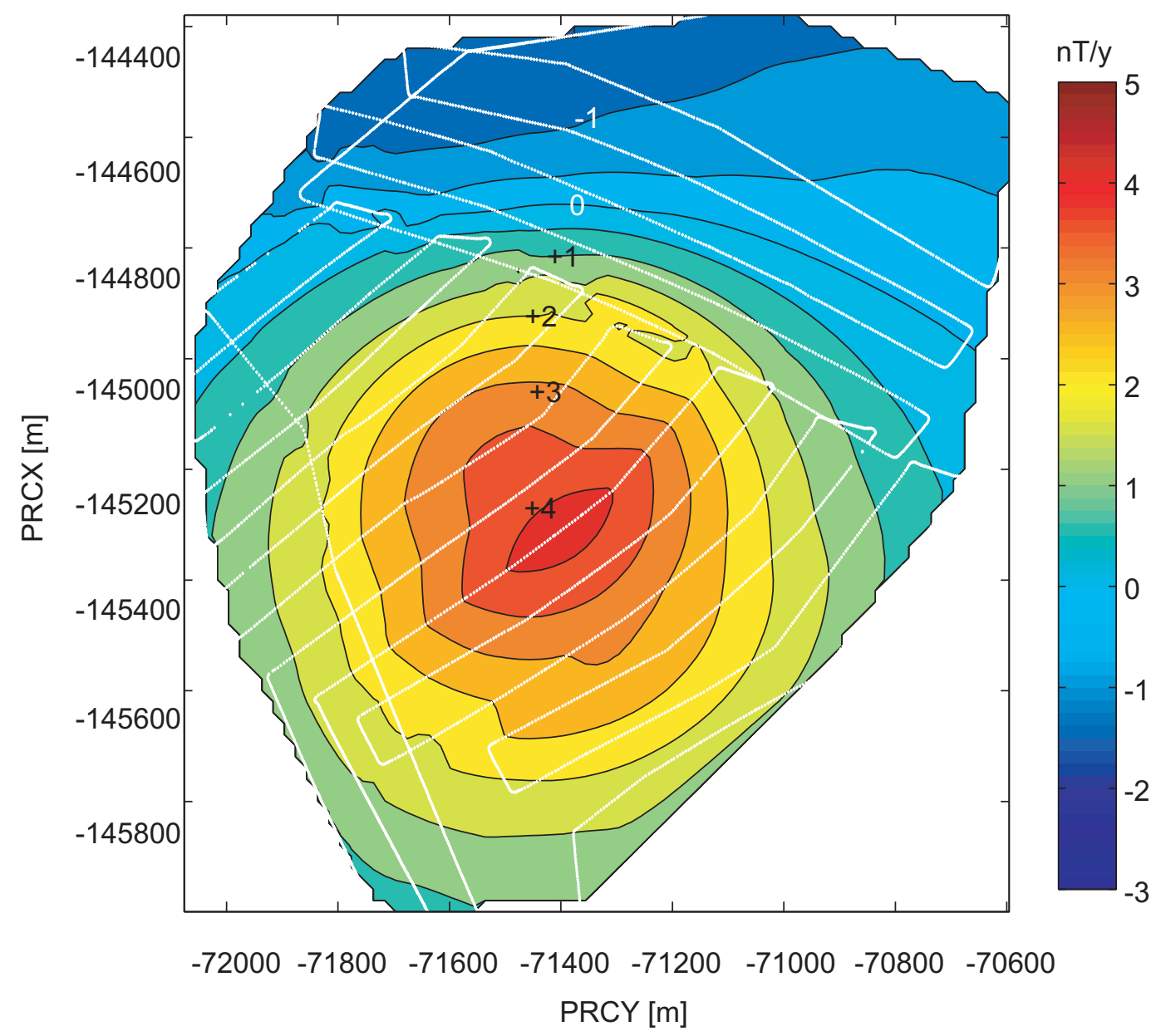

Figure 10 Hashimoto et al. 